\title{
Desenvolvimento do turismo no espaço rural como estratégia de reconversão no Brejo paraibano
}

\author{
Oliveira Ribeiro Josilene* \\ Universidade Federal da Paraíba(Brasil)
}

\begin{abstract}
Resumo: Este artigo tem por objetivo discutir o processo de reconversão social dos sitiantes em pequenos empreendedores no brejo paraibano e identificar a relação entre este fenômeno e o desenvolvimento do turismo no município de Areia. A questão se coloca em função da coincidência entre o momento de inflexão na trajetória dos sitiantes, enquanto grupo social, e a emergência do turismo como atividade econômica estimulada por políticas de desenvolvimento para o Nordeste brasileiro. Pautando-se pela metodologia qualitativa, os dados privilegiados nesse trabalho foram construídos a partir de uma etnografia, realizada entre 2015 e 2016. Dados secundários, obtidos por meio de pesquisa documental e revisão bibliográfica, complementam a análise. A discussão dos resultados contempla a trajetória dos sitiantes da comunidade Chã de Jardim a partir da segunda metade do século XX até o presente, considerando as amplas transformações no mundo rural. Os resultados e as conclusões evidenciam que a reconversão dos sitiantes está condicionada à mudança de valores e à adesão deles ao discurso do empreendedorismo, implicando na racionalização até mesmo dos sonhos, o que ocorreu mais claramente entre os jovens sitiantes com maior escolarização. Constatou-se também que o desenvolvimento do turismo é determinante para 'reconversão produtiva' do próprio território rural, que deixa de ser percebido apenas como agrário e se torna espaço de lazer e entretenimento, situação que veio a fortalecer a percepção de sua complementariedade em relação ao território urbano.
\end{abstract}

Palavras-chave: Turismo rural; Empreendedorismo; Estratégias de reconversão; Novas ruralidade; Sitiantes.

\section{Rural tourism development as a conversion strategy in the Brejo of Paraíba}

Abstract: This article is directed at discussing the process of social reconversion of agricultural hands into small entrepreneurs in the Brejo of Paraíba and at identifying the relationship between this phenomenon and the development of tourism in the municipality of Areia. The question is posed due to the moment of inflection in the agricultural settlers circumstances coincident with the emergence of tourism as an economic activity stimulated by development policies in the Northeast of Brazil. Qualitative research carried out between 2015 and 2016 afforded the valuable ethnographic data included herein. Secondary data, obtained through documentary research and bibliographic review, complement the analysis. The discussion of the results contemplates the story of how the agricultural workers in the Chã de Jardim community have evolved from the second half of the twentieth century through to the present, within the broader context of the widespread and deep transformation of the rural world. The results and conclusions show that the reconversion of the agricultural workers depends upon a change in values with younger more educated workers embracing the discourse of entrepreneurship, and pragmatically pursuing their "dreams". It was also found that the development of tourism is decisive for the productive conversion' of the rural territory itself, which ceases to be perceived only as agricultural and becomes a space for leisure and entertainment, a situation that consolidates its perception as complementary to urban territory.

Keywords: Rural Tourism; Entrepreneurship; Social reconversion strategies; New rural lifestyle agricultural workers.

\section{Introdução}

O Brejo paraibano é uma das 23 microrregiões do estado da Paraíba - situado no Nordeste brasileiro, sendo composta por oito municípios - Alagoa Grande, Alagoa Nova, Areia, Bananeiras, Borborema,

\footnotetext{
Universidade Federal da Paraíba(Brasil); E-mail: osilene.ro2011@gmail.com; https://orcid.org/0000-0002-0943-0846
} 
Matinhas, Pilões e Serraria. Sua fisionomia é caracterizada pela existência de grande quantidade de pequenos lotes de terra (Garcia Jr. 1989; Moreira \& Targino 1997), pertencentes a pequenos proprietários, denominados nesse trabalho de sitiantes $^{1}$. Geograficamente, é definida como uma zona de exceção, por ser mais úmida que o restante da mesorregião do Agreste, da qual faz parte. Entrecortada por serras e planaltos, a altitude e a maior umidade atmosférica condicionam a pluviosidade elevada, resultando em clima mais ameno e em temperaturas mais baixas (Marques, Araújo \& Diniz, 2016). Graça a isso, o Brejo tornou-se uma região de policulturas, tendo sido denominado até mesmo como "celeiro do sertão" (Almeida, 1980) até o fim do século XVIII, quando o cultivo da cana de açúcar tornou-se dominante (Fiúza et al., 1998).

O município de Areia possui uma área territorial de $266,569 \mathrm{~km}^{2}$ e atualmente tem uma população estimada em 22.656 habitantes (IBGE Cidades, 2020), sendo marcado particularmente pela presença de brejos de altitude, com suas peculiares ilhas de floresta de mata atlântica que elevam astaxas pluviométricas e higrométricas (Marques, Araújo \& Diniz, 2016). A fertilidade do solo do município possibilitou o cultivo de policulturas, mas foi a cultura da cana de açúcar, associada ao poder e à dominação dos senhores de engenhos, que mais marcas deixou no patrimônio material e imaterial da cidade, incluindo as relações sociais hiper-hierarquizadas, os casarios da sede do município e os engenhos na área rural.

A patrimonialização da área mais antiga da sede municipal e das encostas sobre as quais a vila foi erguida entre os séculos XVII e XIX, por meio de tombamentos ${ }^{2}$ nas esferas estadual e federal, reflete o reconhecimento institucional não apenas do patrimônio material, mas também da história da aristocracia rural no município. O tombamento pelo Instituto do Patrimônio Histórico e Artístico Nacional (IPHAN), ocorrido em 2005/2006, possibilitou ao município acessar recursos de programas federais como o Monumenta ${ }^{3}$, além de outros voltados à regionalização do turismo, tornando esta atividade relevante para o desenvolvimento econômico local nas últimas décadas.

Em Areia, a atividade turística baseia-se, justamente, na centralidade da paisagem e do patrimônio rural, com ênfase em representações tradicionais e também releituras. Desde 2006, Areia recebe um fluxo regular de 13 mil visitantes, em média, por ano, não contabilizados o fluxo gerado em função de eventos realizados em datas/períodos específicos (tais como Festival Sons e Sabores, Rota Cultural Caminhos do Frio ou o Bregareia), conforme dados da Secretaria de Turismo do município. Em 2014, tal órgão contabilizou 17.129 visitantes apenas no Museu Casa de Pedro Américo ${ }^{4}$, número que, apesar de ser considerado um marco pelo Secretaria de Turismo de Areia (Setur), equivale a apenas 1,04\% do total de (1.649.965 pessoas) turistas que visitaram o estado da Paraíba no mesmo período, conforme dados da Empresa Paraibana de Turismo (PBTur, 2016).

Na comunidade rural Chã de Jardim, com a qual mantém-se contato desde 2013, os sitiantes estão envolvidos na produção da oferta turística. Os membros jovens da comunidade, que foi transformada em caso de sucesso pelo Serviço Brasileiro de Apoio às Micro Pequenas Empresas (SEBRAE), têm buscado a própria reconversão social dentro daquilo que pode ser interpretado como um novo ciclo econômico no município, o qual parece estar atrelado às novas propostas de desenvolvimento que têm como princípio norteador políticas públicas que valorizam a cultura como um recurso 'gerenciável' - invocado para resolver problemas que antes correspondiam ao âmbito da economia e da política, incluindo a geração de emprego e renda, como afirma Yúdice (2002) -, no engate com a indústria do lazer, entretenimento e turismo.

No âmbito deste trabalho, discute-se: Como e quando os sitiantes da Chã de Jardim passam a participar da oferta turística do município de Areia? O que significa para este grupo social tornar-se 'empreendedores do turismo'? Qual a relação entre o processo de desenvolvimento desse setor no município e a reconversão dos sitiantes? O objetivo é entender as condições de possibilidade da reconversão social dos sitiantes a partir da trajetória do grupo dentro do contexto histórico de evolução do turismo na cidade de Areia. Em outras palavras, desejamos entender como surgiu e se efetuou essa reconversão, considerando que: 1) outrora, em um passado não muito distante, a possibilidade de mobilidade social sequer existia, já que a tendência entre os agricultores familiares era que seus filhos seguissem o mesmo caminho, isto é, continuassem vivendo economicamente da agricultura e para manutenção de suas famílias; 2) havia uma taxa alta de analfabetismo, muita pobreza no meio rural nordestino e o acesso à educação era restrito; 3) o espaço e a população rural, bem como suas tradições, eram percebidos como atrasados e avessos a mudanças. Para responder às questões mencionadas e alcançar tal objetivo, toma-se por base a abordagem bourdieusiana das lutas simbólicas e a teoria da prática, considerando que as ideias, as percepções, ou seja, a subjetividade e o mundo simbólico, influenciam a realidade do mesmo modo que são impactadas por esta última. 
Adepto ao trabalho empírico, o sociólogo Pierre Bourdieu identificou que há uma correlação profunda entre a maneira de pensar e a maneira como a sociedade se organiza, logo, entre o simbólico e o concreto. Para entender e explicar como a ordem social se estabelece, como ela se transforma e como as estruturas mentais tendem a se reproduzir no mundo vivido, Bourdieu reelaborou o conceito de habitus ${ }^{5}$ e criou outros como de 'espaço social' e o de 'reconversão social'. Tais conceitos revelaram-se úteis para compreender as lutas simbólicas que estão atreladas à ascensão social dos sitiantes à categoria de empreendedores bem como a inserção deles na oferta turística da cidade de Areia, oferta esta inicialmente empreendida e dominada pelos herdeiros da aristocracia rural, com foco no patrimônio material.

A discussão está organizada em quatro seções: na próxima seção, apresenta-se sumariamente alguns conceitos mobilizados na análise dos dados; na seção 3, discorre-se brevemente sobre a metodologia adotada; na seção 4, discute-se os resultados, trazendo, primeiramente, o contexto histórico e social em que ocorre o processo de reconversão dos diferentes grupos sociais no Brejo paraibano; na seção 5 , trata-se da relação entre a reconversão dos sitiantes e as etapas de desenvolvimento do turismo em Areia, distinguindo-se como ocorreu a reconversão produtiva do território rural; na seção 6, aponta-se o significado do empreendedorismo e as estratégias de reconversão social dos sitiantes da Chã de Jardim.

\section{Dos conceitos e referências aplicados à pesquisa}

O turismo, atividade moderna que privilegia o tempo livre em oposição ao tempo de trabalho e que pressupõe de seus praticantes a posse de capital econômico e/ou cultural - logo, uma certa distância da necessidade -, torna visível e acentua ainda mais a complexidade das relações entre a sociedade e os territórios sobre os quais ela constrói e edifica sua cultura. Inscrito no âmbito das novas ruralidades, o turismo no espaço rural (TER) tem evidenciado a reinvenção desse território como espaço de lazer e consumo das classes urbanas. Com efeito, a turistificação do campo é uma das múltiplas faces que caracterizam as novas ruralidades, contribuindo diretamente para a emergência de novas interpretações do mundo rural (Carneiro, 2012).

A atividade turística no meio rural manifesta-se no contexto da multifuncionalidade dos espaços rurais, conceito que surgiu em consonância com a reconfiguração das políticas de desenvolvimento, no âmbito internacional. Assimilando o discurso da sustentabilidade, o território rural passou a ser visto como uma qualidade que interessa não só aos seus habitantes, mas ao conjunto da sociedade, devendo ser preservado e valorizado (Wanderley, 2003).

Nessa perspectiva, desde os anos 1950, o turismo em espaço rural é reconhecido como estratégico para o desenvolvimento regional em muitos países ao norte e centro da Europa e, a partir dos anos 1970, nos países do sul da Europa e Estados Unidos. Mas apenas a partir da década de 1980 pelo Brasil, a Argentina e o Uruguai (Bramante, Maglio, Roque, 2012). No Brasil, a turistificação do campo tem se propagado pouco a pouco, encontrando como aliado os Governos, em suas diferentes instâncias - federal, estadual e municipal. Ressalta-se que o Governo Federal passou a incluir oficialmente o turismo como inerente a exploração econômica em meio rural apenas em 2015, e desde então vem promovendo linhas de crédito para estimular este segmento de mercado por meio do incentivo ao empreendedorismo em meio rural.

Apesar da multidisciplinaridade e da polifonia que caracterizam os estudos e as definições de empreendedor e de empreendedorismo, há um certo consenso sobre o fato de que o discurso do empreendedorismo elege a empresa capitalista contemporânea como centro do processo socioeconômico de geração de riqueza, de renda e de trabalho (Costa, Barros, Carvalho, 2011). Segundo essa abordagem, a educação torna-se um mero instrumento de formação do 'capital humano' necessário ao desenvolvimento do 'novo espírito do capitalismo', em que cada indivíduo é responsável por si mesmo, por seu sucesso ou fracasso, e, assim, deve gerenciar e investir em sua carreira como se fosse uma empresa - "eu-empresa" (Costa, 2009).

Ao seu turno, o empreendedor é percebido como alguém que tem "iniciativa e coragem de assumir riscos" dentre outras qualidades excepcionais, agrupadas na ideia de "espírito empreendedor". De acordo com a literatura especializada, o espírito empreendedor está diretamente associado, de um lado, a valores individualistas, como autonomia, liderança e iniciativa; de outro, ao próprio processo de reinvenção do capitalismo e, nesse caso, o empreendedorismo é uma forma de oxigená-lo ou atualizá-lo (Barbosa, 2016).

Entendido como a criação de uma nova organização que introduz um novo produto, serve ou cria um novo mercado ou utiliza uma nova tecnologia num ambiente rural (Sancho, 2010), o empreendedorismo no meio rural brasileiro vem sendo estimulado por órgãos públicos ${ }^{6}$ e não governamentais. Essas entidades costumam tratar o "empreendedor rural" como sinônimo de "empresário do campo", incentivando e treinando-o para compreender a propriedade como uma empresa, ignorando que o sítio camponês é 
mais do que uma propriedade, ele é a unidade elementar a partir da qual os sitiantes organizam as relações sociais, o trabalho e definem seu modo de vida (Heredia, 1979; Woortmann, 1983; Woortmann, 1990; Oliveira, 2018). Nessa perspectiva, o empreendedorismo pode ser compreendido como um discurso pautado na ideologia capitalista, que pretende converter o sitiante em um "empresário rural", um pequeno-patrão, capaz de assumir riscos calculados, tomar a iniciativa, responsabilizar-se pelo "sucesso" de seu negócio, gerar renda para si e para outros (Oliveira, 2018). É dentro dessa conjuntura que se pode falar de reconversão produtiva do espaço rural e de reconversão social dos sitiantes, entendendo que o incentivo à adesão do pequeno produtor rural às regras e aos princípios capitalistas, entraria supostamente em choque com os valores e princípios tipicamente campesinos. Princípios esses que têm como categorias nucleares da vida camponesa religião, terra, trabalho e família, e como princípios organizativos: a honra, a hierarquia e a reciprocidade (Woortmann, 1990). Dessa forma, o conjunto das mudanças contemplam tanto aspectos sutis como mais profundos, objetivos e subjetivos, pois se tornar um empreendedor significa para os sitiantes uma mudança de racionalidade, logo, uma mudança cultural.

Por outro lado, a assimilação do turismo no espaço rural como atividade econômica pelos agricultores familiares e as transformações nas formas de trabalho decorrentes disso conformam a noção de "reconversão produtiva". Tal noção parece útil para pensar a mudança social como um processo, em que agentes sofrem efeitos de mudanças não intencionais ou agem deliberadamente sobre si mesmo ou sobre um objeto (Bourdieu, 2007; Cunha, 2009), no caso, sobre o território rural e sobre a cultura camponesa.

Nesse sentido, entende-se que a reconversão produtiva não implica necessariamente transformações radicais, mas principalmente deslocamentos, reestruturações, transformações que, sendo significativas, não representam um rompimento completo com o passado (Menezes; Malagodi; Moreira, 2013). Na verdade, tal noção é derivada e está conectada à noção bourdieusiana de reconversão social, a qual da conta de "deslocamentos em um espaço social", bem como da "reestruturação do sistema das estratégias de reprodução social", que podem levar à "transformação estrutural" da dinâmica das posições sociais dos agentes na sociedade (Bourdieu, 2007).

Conforme Bourdieu (2007), as possíveis estratégias empreendidas/adotadas pelos agentes visando a reconversão social são influenciadas diretamente pelo capital cultural acumulado e pelas disposições sociais adquiridas por eles ao longo da vida, ou seja, pelo habitus. Em outras palavras, sabendo que o habitus corresponde a disposições duráveis que determinam estilos de vida, gostos e valores, deve-se considerar a hipótese que a reconversão social se circunscreve em um horizonte definido de possibilidades que estejam em conformidade com as posições do sujeitos no espaço social. Em síntese, pode-se afirmar que, para Bourdieu (1996 [1994]), o espaço social corresponde a um "campo de forças" e um "campo de lutas", onde os diferentes agentes enfrentam-se e empreendem diferentes estratégias para conservar ou aumentar seu capital e poder simbólico e, com isso, manter suas posições de dominantes. Dessa forma, este trabalho aproxima-se e dialoga com a teoria da prática do sociólogo Pierre Bourdieu, ilustrando como os agentes convertem capital cultural e social em capital econômico e simbólico, promovendo a própria reconversão.

\section{Metodologia}

Para efeito de classificação, entende-se que esta pesquisa tem caráter qualitativo e enquadra-se na categoria descritivo-explicativa, tendo em vista que preocupa-se em apontar as causas e efeitos e observar o fenômeno da reconversão social dos sitiantes no quadro mais amplo da realidade, isto é, explicar a emergência da participação dos sitiantes no mercado do turismo rural. Realizada em diferentes etapas, entre 2013 e 2016, a investigação compreendeu a revisão de literatura, o levantamento documental e a realização de um estudo etnográfico na comunidade rural Chã de Jardim, durante seis meses, estabelecendo-se residência no local entre setembro de 2015 e março de 2016. Como ferramentas de construção dos dados, recorreu-se também a entrevistas (semiestruturadas e estruturadas), a aplicação de questionários e a registros fotográfico e em diário de campo.

Dessa forma, a proposta metodológica integrou diferentes métodos e técnicas de construção de dados, de modo que é possível identificar uma aproximação à noção de triangulação metodológica e, consequentemente, o distanciamento de monométodos (ou método único). A triangulação seria, pois, por analogia, um recurso para "fazer fotografias" dos sujeitos pesquisados com várias lentes e em diferentes ângulos e perspectivas, as quais podem revelar as muitas faces de um mesmo fenômeno. Dito de outro modo, "a 'triangulação' não se cinge unicamente à seriedade e à validade, mas permite um retrato mais completo e holístico do fenômeno em estudo" (Duarte, 2009, p. 14). 
Este artigo inclui dados secundários, produzidos a partir do levantamento documental, obtidos em arquivos públicos e virtuais dos órgãos federais, estudais e municipais, além de monografias e reportagens em jornais impressos e eletrônicos sobre o turismo em Areia. Coloca-se em relevo os dados primários, oriundos da observação e das entrevistas semi-estruturadas realizadas com 30 sitiantes da Comunidade Chã de Jardim, dentre eles a liderança local. Estes últimos foram submetidos à análise crítica do discurso, tendo como preocupação não esmagar os agentes, de modo a destacar as representações do mundo dos dominados e a participação dos sitiantes no processo de construção da realidade, a partir de suas percepções de mundo e da produção de sentidos na vida cotidiana.

\section{Contexto histórico e social do processo de reconversão no Brejo paraibano}

Na região Nordeste, a cultura canavieira foi a principal atividade econômica desde o início da colonização, embora tenha se concentrado predominantemente nas áreas originalmente de mata atlântica, próximo ao litoral. Na microrregião do Brejo paraibano, ela viveu períodos de expansão e retração, em que, respectivamente, voltava-se para o mercado externo ou para o mercado interno (Fiúza et. al, 1998), contudo, sem jamais ser definitivamente abandonada. O que explica sua presença até os dias de hoje e a existência de um registro significativo do funcionamento dos engenhos como sistema econômico, em que predominava formas particulares de dominação. $\mathrm{Na}$ área rural, esse registro é constituído por um conjunto de edificações, incluindo: casa-grande, engenho/fábrica de cachaça/rapadura, capela, formando aquilo que Almeida (1994) chama de "triângulo característico dos engenhos" da microrregião do Brejo. Atualmente, tais edificações são consideradas atrativos dentro das práticas turísticas no espaço rural, tanto quanto as reminiscências e representações desse passado.

Durante os séculos XVIII e XIX, os senhores de engenho dominavam a cena local, acumulando prestígio político, econômico e poder simbólico. Porém, a chegada das usinas ${ }^{7}$ no Brejo paraibano, ainda na primeira metade do século XX e sua consolidação na segunda metade, implicou na reconfiguração da economia agrária e das relações de poder na região. Primeiramente, convém destacar que o usineiro se diferenciava dos senhores de engenho não apenas pela posse de maior volume de capital econômico, mas sobretudo pela adoção da racionalidade mercantil, portanto, de práticas capitalistas. Essa postura levou à expropriação da terra de moradores e dos pequenos produtores (que não tinham a posse legal da terra), pois nem aos senhores de engenho nem tampouco aos usineiros interessava mais que pequenos sítios e casas de moradores estivessem espalhados por suas propriedades, o que gerou muitos conflitos no campo.

A acentuação dos conflitos rurais que insurgiram no Nordeste, em decorrência de tal situação, pressionou o Governo Federal a agir, resultando na consolidação dos direitos do trabalhador rural, com a aprovação do Estatuto do Trabalhador Rural, por meio da Lei n. 4.214 de 1963, e do Estatuto da Terra, por meio da Lei 4.504 de 1964 (já durante o Regime Militar). É nessa perspectiva que as consequências da chegada das usinas/usineiros, com suas práticas modernizantes da plantation, foram contraditórias e ambíguas. De um lado, representou a expropriação da terra de trabalho, de outro, contribuiu diretamente para abalar o sistema de dominação tradicional e personalizada dos senhores de engenhos, enfraquecendo seu poder progressivamente, até estes tornarem-se meros fornecedores de matéria prima para as usinas, ou seja, subordinados aos usineiros (Heredia, 1989; Garcia Jr, 1989).

Entretanto, a decadência da oligarquia açucareira não extinguiu o poder desse grupo social, que optou por duas estratégias ${ }^{8}$ principais: a reconversão produtiva, tornando-se pecuaristas e/ou diversificando ainda mais o uso da terra com cultivos alternativos, como o da banana (IPHAN, 2009), porém, sem abandonar definitivamente a cana de açúcar; e o investimento na escolarização e carreira dos filhos, que foram liberados da condição de herdeiros da propriedade rural e, assim, vão se tornar advogados, médicos, servidores públicos e em alguns casos políticos, reproduzindo-se como uma classe social urbana, residente em cidades metropolitanas, vindo inclusive a contribuir com o trabalho de invenção das novas instituições públicas no país (Garcia JR, 1993).

\section{Desenvolvimento do turismo em Areia e reconversão do território rural}

É possível distinguir três estágios no processo de evolução do turismo no município de Areia: rudimentar, abrangendo as décadas de 1930 a 1980; potencialização, concentrando-se na década de 1990; consolidação, a partir dos anos 2005. Dentro de cada estágio pode-se elencar uma série de fatos e ações 
implementadas por agentes públicos, com atuação em nível local ou nacional, e agentes individuais, que juntos irão induzir o desenvolvimento do turismo e, direta ou diretamente, a inserção da Comunidade Chã de Jardim nesse processo.

Figura 01: Estágios da evolução do turismo em Areia.

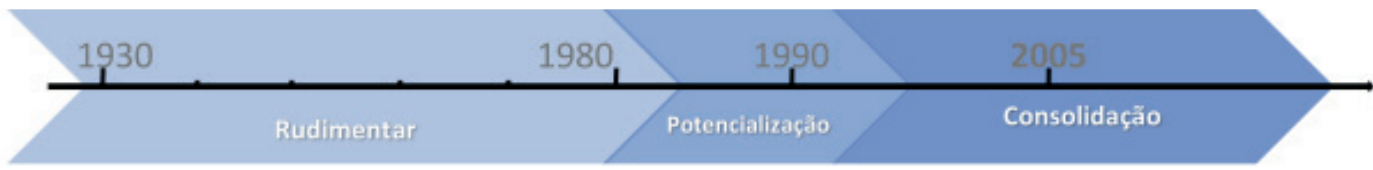

Fonte: Elaboração própria da autora, 2017.

A criação da Escola de Agronomia da Parayba, em 1936, é um marco para o estágio rudimentar, durante o qual não se falava em turismo em Areia. Todavia, foi durante esse estágio que rodovias foram construídas, melhorando as vias de comunicação e acesso à cidade, e esta se tornou "referência" em cultura na Paraíba. A federalização da Escola de Agronomia, em 1950, e sua integração à Universidade Federal da Paraíba, em 1968, com a posterior abertura de mais cursos superiores, geraram um fluxo crescente de novos alunos vindos de diferentes regiões da Paraíba e até mesmo de outros estados nordestinos. Nessa fase, merece destaque também o papel exercido pelo Colégio Santa Rita, que funcionava em regime de internato e educava as meninas da elite da região do Agreste paraibano, que recebiam uma educação religiosa tradicional, incluindo conteúdos como línguas, música (canto e piano), pintura, ciências, educação doméstica, bordado entre outros, ministrada por freiras alemãs, desde 1937 (Camacho, 2013).

Talvez o mais importante e, certamente, um dos elementos mais emblemáticos para construção da imagem do lugar (e que povoa o imaginário social sobre a cidade até hoje), seja o fato de Areia ter tido sua própria "Era dos Festivais", com a realização do "Festival de Artes de Areia", entre os anos 1976 e 1982. Assim, Areia entrou para a vanguarda no estado da Paraíba, tornando-se também um roteiro para comerciantes que vinham dos estados de Pernambuco e do Rio Grande do Norte (Magalhães, 2009), além de atrair grupos artísticos e intelectuais para debates e apresentações, anualmente. É certo que esses festivais trouxeram artistas e visitantes para cidade, ainda que em pequeno número, criando demanda por meios de hospedagem e serviços de alimentação. Vale destacar que, nessa época, os sitiantes (e o mundo rural) eram percebidos apenas como elementos da paisagem cultural, não participando efetivamente deste evento, a não ser na condição de "curiosos". Isso irá mudar na etapa seguinte, conforme descreve-se a seguir.

A década de 1990 compreende o período que denomino de potencialização, durante o qual o turismo começa a ser pensando como uma alternativa para a crise econômica e do emprego, gerada pela falência da Usina Santa Maria. Período que coincide com a chegada de recursos federais para o primeiro Programa de Desenvolvimento do Turismo (PRODETUR I) no estado. Nessa fase ocorre a criação da Reserva Mata Pau Ferro, em 1992, a qual foi contemplada, em 1996, com um Projeto de Ecoturismo, financiado pelo Ministério do Meio Ambiente e pelo Banco Mundial e gerido de forma conjunta pela UFPB, Sudema e Prefeitura Municipal de Areia. Desde então, a Reserva passou a atrair pesquisadores interessados em conhecer um dos últimos remanescentes de mata atlântica de brejo de altitude, servindo, eventualmente, de espaço para aulas de campo para estudantes e universitários.

A decisão tomada pela UFPB, durante o estágio de potencialização, de não mais construir residências universitárias para novos alunos do Campus de Areia parece ter contribuído para desencadear o surgimento de novos meios de hospedagem em Areia. Conforme os relatos, a decisão favoreceu o desenvolvimento de um "pseudo-mercado" imobiliário de aluguel de apartamentos e casas para estudantes e forçou a aparição de novos meios de hospedagem na cidade. Nessa época ocorre também a volta do Festival de Artes de Areia (em duas edições, em 1998 e 1999) e a criação do I Festival Brasileiro da Cachaça e da Rapadura, em 1997, que se tornará conhecido nas edições seguintes como Bregareia ${ }^{10}$, que chegou a receber um público de cerca de 60 mil pessoas.

Nas suas 16 edições, entre 1997 e 2016, a programação do evento incluiu, além da "parte acadêmica" (com seminários, palestras e visitas técnicas a engenhos/fábricas de cachaça) e a degustação, brincadeiras de cunho jocoso, que versavam sobre os efeitos do consumo da cachaça ou o uso de fantasias de "brega". Ao reunir um estilo musical que, de acordo com Fontanella (2005) e Soares (2017) é apreciado 
pelas camadas populares e que tem por características principais letras sentimentais e simplicidade dos arranjos musicais - o brega; um produto originalmente popular - a cachaça; e incentivar que o público participe, caracterizando-se como "bregas" (cafonas), esse festival, que exalta a irreverência do personagem do bufão, assume uma matriz cultural integralmente popular, diferindo da proposta do Festival de Artes de Areia. Assim, a população local, incluindo os sitiantes, começa a participar deste evento, vivendo a inversão social dos papeis por meio do personagem burlesco ou sendo representado por ele e pelo estilo brega, de modo a rir-se de si mesmo. Portanto, trata-se de uma inclusão dos sitiantes muito mais simbólica do que concreta, nesse momento.

O estágio de consolidação da cidade de Areia como destinação turística corresponde ao período em que se verifica o aumento progressivo do fluxo de turistas e a acentuação do número de meios de hospedagem ${ }^{11}$ e de restaurantes (Galvão, 2012), sendo o ano de 2005 um marco temporal importante. Nesse ano, a Reserva Mata Pau Ferro é convertida em Parque Estadual e, ano seguinte, os sitiantes da Chã de Jardim passam a explorá-la para oferta de serviços turísticos, tornando-se de modo extraoficial seus gestores. Atualmente, eles oferecem serviços de piqueniques, de trilhas guiadas a pé, a cavalo e em bicicletas, além de promoverem encontros de capoeira, de orientação etc. dentro do Parque, contando com autorizações da Sudema. Em 2013, eles construíram o Restaurante Rural Vó Maria, nas margens da PB 008, exatamente em frente à Mata Pau Ferro.

Nesse estágio também ocorre uma nova tentativa de retomar a realização do Festival de Artes de Areia, com algumas modificações no formato. Assim, o evento é realizado por mais quatro edições, nos anos 2005, 2008, 2011 e 2012. Atualmente, o festival foi absorvido pela Rota Cultural Caminhos do Frio, ocorrendo de forma integrada dentro deste projeto, que teve sua primeira edição em 2006. Os "Caminhos do Frio", como é conhecido, congrega forte presença de representações da ruralidade na composição da programação, além de algumas atividades nas áreas rurais, com foco no contato com a natureza. Atualmente esse projeto contempla nove municípios ${ }^{12}$ e é realizado anualmente, desde 2006, de julho a setembro (meses mais frios do ano no Nordeste brasileiro).

Todavia, o fato mais relevante do período foi o tombamento do conjunto Histórico, Urbanístico e Paisagístico de Areia como Patrimônio Nacional, em 2005, pelo IPHAN, homologado e publicado no Diário Oficial da União através da Portaria n. $73^{\circ}$, em 2006. Apesar de criticado por não ter incluído a população local no processo de tombamento e por não contemplar o patrimônio rural da cidade, o tombamento federal pode ser considerado um divisor de águas no desenvolvimento do turismo. É nessa fase que o território rural se tornou alvo da especulação imobiliária, com surgimento de condomínios rurais de luxo voltados para atender os neorurais - um setor da população urbana que faz investimento no campo, adquirindo terrenos e construindo suas residências secundárias (Giuliani, 1990). Durante a pesquisa de campo, verificou-se a existência de quatro (04) condomínios de campo e dois (02) loteamentos na área rural de Areia, todos criados depois do processo de tombamento federal.

Tal processo tem desencadeado transformações no conjunto do território, ou seja, na sede urbana do município e no campo. Na área urbana, observa-se a expansão da oferta de serviços nos segmentos de hospedagem e alimentação, com abertura de restaurantes, supermercados e pousadas, por exemplo. No campo, novos usos e práticas de trabalho veem se desenvolvendo. Como por exemplo, durante a pesquisa de campo, verificou-se que dos nove engenhos ainda em "atividade ${ }^{13}$ " pelo menos dois foram reconvertidos integralmente em empreendimentos de lazer e turismo e outros passaram a receber e/ ou desenvolver atividades para turistas.

Os dados levantados permitem concluir que o desenvolvimento das atividades turísticas no Brejo paraibano e o processo de "turistificação" de Areia fazem parte, primeiramente, das estratégias de reconversão das classes dominantes. Todavia, a atuação dos agentes de desenvolvimento e representantes do Estado tem colaborado para transformar sitiantes, herdeiros de engenhos e descendentes da aristocracia rural em empreendedores do turismo. Assim, tal como observa Alves (2017), verifica-se o agenciamento das tradições rurais, como a devoção secular católica e a correspondente representação visual dos santos, a festa da colheita do milho, a culinária característica, o forró pé de serra, o cangaço, as quadrilhas juninas, enfim, uma espécie de encenação e representação de um Nordeste rural, que é convertido em atração turística e atividades lúdico-culturais.

Dentro desse jogo, os sitiantes e a ruralidade foram assimilados e passaram a integrar a oferta turística do município tardiamente, já no estágio de consolidação do turismo, que se inicia em 2005/2006, junto com o tombamento de Areia pelo IPHAN. A reconversão do espaço rural em espaço de lazer e turismo permitiu a emergência do protagonismo dos sitiantes da comunidade Chã de Jardim, que não são mais vistos apenas "curiosos" nos eventos da cidade, mas sim partícipes da oferta turística, atestando a vitalidade das novas ruralidades. 


\section{Turismo e estratégias de reconversão social dos sitiantes da Chã de Jardim}

Distante apenas $7 \mathrm{Km}$ da sede do município, a comunidade Chã de Jardim situa-se às margens da PB 008 e é constituída por cerca de 352 habitantes (IBGE, 2015). Desde 2006, a comunidade integra a oferta turística do município de Areia por meio da comercialização de serviços concebidos e gerenciados pelos próprios sitiantes, inscrevendo-se na categoria de Turismo de Base Comunitária. Os serviços oferecidos compreendem: o Restaurante Rural Vó Maria, fundado em 2013, onde é oferecido, exclusivamente, pratos "tradicionais", cuja base da preparação são ingredientes e insumo adquiridos preferencialmente dos locais (como galináceos, grãos e tubérculos); uma loja/comércio, onde são vendidos guloseimas, "produtos da região" (cachaças, rapadura etc.) e as peças de artesanato produzidas por mulheres da comunidade; as trilhas guiadas e vivências na Reserva Estadual Mata Pau Ferro, em frente da qual fica o restaurante; e um camping, chamado de Hotel de Barracas, que passou a funcionar em dezembro de 2017 (Oliveira, 2018).

A comercialização de tais atividades, propostas e organizadas pelo grupo a frente da Associação para o Desenvolvimento Sustentável da Chã do Jardim (Adesco), gerava até 2018, aproximadamente, 30 postos de trabalho diretos, que contemplavam as atividades de guias locais, de garçons e garçonetes, de cozinheiros(as), de vendedores, gerentes, cantores/animadores dentre outras ocupações, exercidas essencialmente pelos sitiantes jovens. De acordo com informações da liderança local, o conjunto dos empreendimentos alcançou um faturamento recorde em 2016, quando atingiu à cifra 585 mil reais naquele ano, fato amplamente celebrado, pois "São mais de meio milhão que fica aqui, na nossa comunidade!" (Luciana Balbino, 35 anos; líder comunitária; 01/03/2016).

Não obstante o fato de que a inserção dos sitiantes e da Comunidade no turismo seja um fenômeno recente (pouco mais de uma década), o processo de reconversão e ascensão social deste grupo começou muito antes. Como foi descrito, o processo pelo qual moradores de engenho e sitiantes deixaram de ser submetidos diretamente aos senhores de engenho e fazendeiros tem início a partir da desestruturação do ciclo econômico da cana de açúcar, graças ao fim dos incentivos fiscais governamentais, e da consolidação do poder do Estado moderno, com sua ação tecnocrática e seu aparato jurídico, que permitiu aos trabalhadores rurais o reconhecimento de direitos trabalhistas (Sigaud, 1979 e 1996). Além disso, deve-se considerar como passos fundamentais o acesso a benefícios sociais como aposentadoria, licença maternidade e, mais recentemente, ao bolsa família e a linhas de crédito para agricultores familiares.

$\mathrm{Na}$ longa duração, dentre as principais estratégias de reconversão empreendidas pelos sitiantes, destacam-se: 1) a migração para as regiões Sul e Sudeste do país, especialmente nas décadas de 1950-1960, fenômeno que foi amplamente analisado por Garcia Jr. em seu livro "O Sul: caminho do roçado"; 2) a pluriatividade, entendida como característica ao modo de vida camponês, ao passo que muitos agricultores do Brejo foram e são também pequenos comerciantes nas feiras livres, e que o assalariamento temporário auxilia na manutenção e, frequentemente, subsidia os investimentos na terra/agricultura dos que permanecem exercendo a atividade agrícola; 3) e a escolarização, compreendida conforme a perspectiva bourdieusiana como uma estratégia consciente ou inconsciente de reconversão que objetiva a acumulação e manutenção de capital cultural e social familiar. Salienta-se que, no caso do Brejo paraibano, os dados coletados sugerem que a migração das gerações passadas "financiou" a maior escolarização da geração subsequente, que agora ou tenta promover a própria reconversão ou aposta na reconversão dos filhos (Oliveira, 2018). Convergentes quanto à tendência ao assalariamento das populações rurais, essas estratégias possibilitam, no mínimo, a reconversão produtiva dos sitiantes e a assimilação de novas práticas de trabalho e novos valores, resultando em mudanças materiais e simbólicas, logo, objetivas e subjetivas.

Exemplificando, a seguir transcreve-se a fala da líder comunitária da Chã de Jardim, Luciana Balbino, que participou do programa Empretec - o qual adota uma metodologia da Organização das Nações Unidas - ONU e se volta para formação de empreendedores, oferecendo um treinamento comportamental que visa transformar a conduta dos indivíduos -, a convite do Sebrae, em 2012, e abriu seu restaurante em 2013, a partir do plano de negócio que montou durante a capacitação. Com efeito, a participação no curso mudou a sua forma de pensar, conforme ela mesma relata:

[...] na minha cabeça, as coisas aqui, a polpa de fruta e tal, isso era para dá emprego aos outros, mas não para mim. Porque o meu emprego era eu passar num concurso público. E num caía a ficha na minha cabeça que eu produzindo um determinado, uma determinada coisa, e vendendo, no final isso ia ser meu salário. Porque eu imaginava que a pessoa tinha que vender coisa demais para arrumar um salário.

E só quando eu fiz um Empretec foi que eu descobri, porque no final um dos professores deu um depoimento assim, que... "enquanto eu estou aqui com vocês, os meus colaboradores, empregados, 
eles estão trabalhando para gente obter os produtos, para vender, para que possa tirar meu salário e o salário deles." E eu num sei por que, aí caiu a minha ficha que eu podia vender os produtos que ficaria um lucro, que era o meu salário. [...] Porque até então eu continuava naquela que tudo aí era para "dá um agrado as pessoas". Mas para os outros, mas para mim não. Para mim eu tinha, eu tinha que ter um salário certo no fim do mês. [...] Só que aí, no Empretec também, foi quando veio aquelas coisas, que você tem que trabalhar com metas. Se você quer vender cem quilos de polpa de frutas, existe várias estratégias para você vender aqueles cem quilos. [...] Lá no Empretec eu descobri que eu sou uma empreendedora. Eu descobri que se eu colocar metas e eu fizer tudo, eu vou consegui alcançar aquelas metas. E que não precisa ter medo. Que empreendedor corre risco mesmo. (E31: Luciana Balbino, 35 anos; líder comunitária; 04/03/2016).

Dois pontos merecem atenção na fala líder, especialmente quando reflete sobre sua trajetória de empreendedora: o abandono do medo de assumir risco e a aceitação da ideologia de empregador/patrão. A "disposição para assumir riscos" é uma das dez características comportamentais trabalhadas com rigor dentro do Empretec, curso em que Luciana afirma ter "descoberto" ser uma empreendedora e estar preparada para correr riscos, utilizando-se das ferramentas e seguindo um processo de planejamento racional: definir objetivos, traçar metas e elaborar estratégias, executar e avaliar os resultados das ações. A noção de "metas", referida a algo alcançável pelo empenho e esforço pessoal em um determinado período de tempo, afetou significativamente a forma de trabalhar e as percepções da líder comunitária, ao ponto dela afirmar, quando questionada sobre seus sonhos: "eu num sei se eu tenho sonhos, eu sei que eu tenho metas". O depoimento de Luciana Balbino sugere que o "espírito empreendedor" é estimulado dentro do Empretec a partir da reconversão da posição de empregado em empregador, o qual obtém seu salário graças à utilização da força de trabalho de outras pessoas - os empregados.

Paralelamente, o acúmulo de capital cultural (via escolarização) representa para os sitiantes uma conquista, a partir da perspectiva da trajetória da classe e do microcosmo da vida comunitária, posto que, anteriormente, apenas os filhos da aristocracia rural tinham acesso à educação superior. A maior escolarização tem um duplo efeito positivo: a elevação da autoestima e a ampliação do capital social e cultural dos jovens sitiantes. Além disso, ela será responsável pelo desenvolvimento e incorporação de novas disposições sociais para o trabalho e interação social, que são aprendidas pelo e graças ao trânsito em espaços antes reservados à elite, tal qual o ambiente universitário. Consequentemente, ocorre um incremento do status social e das possibilidades de ingresso no mercado de trabalho. Algo destacado pelos próprios sitiantes e pelos agentes intermediários.

De modo geral, as instâncias intermediárias - a exemplo do Sebrae e de outras entidades não governamentais incumbidas da implementação das políticas públicas para o desenvolvimento rural e econômico-, são responsáveis por formatar a oferta turística do município, ensinando os empreendedores de Areia a identificar e a como satisfazer as expectativas dos "turistas". Pode-se dizer que os intermediários "identificam o olhar do turista", graças ao capital cultural que possuem, ao fato de adotar certo estilo de vida e de se inserir/pertencer eles próprios às camadas urbanas interessadas na visitação do meio rural e na cultura popular, traduzindo e ensinando os empreendedores e sitiantes a atender "o gosto" dos turistas. Os cursos de capacitação, dos quais vários jovens sitiantes têm participado, e as consultorias oferecidas pelos intermediários são os meios pelos quais esse conhecimento é transferido e compartilhado, como atesta a seguinte fala:

E40: Teve um curso que foi "de olhar". A gente pegou os meninos lá [em Areia] [...] Aí a gente marcou uma visita para o museu Ricardo Brennand, lá em Recife. Aí pegou os alunos, levamos 40 meninos, professor e tal, no ônibus. "- Só que o negócio é o seguinte, a gente não vai lá para ver o museu. A gente vai ver como é que o museu se estrutura: Como é isso, como é aquilo..." Aí foi orientando os meninos, sabe. Aí eles começaram a olhar o museu com outro olhar. Outra coisa que ela [arquiteta responsável pelo curso] fazia, de vez em quando, era excursão fotográfica. Ela saía pela cidade trazendo máquinas e fotografando. Pá, pá, pá, pá. E depois a gente pegava, imprimia as fotos todinhas. E cada um, que foi o autor das fotos, ia explicar por que que ele fotografou e o que é que ele estava achando, para depois a gente fazer um concurso. E fazia uma exposição das fotos selecionadas. [...] Quando a gente mandou aquele quadro [Cristo Morto, de Pedro Américo] para lá, para ser restaurado, eu consegui a passagem para os meninos e para duas professoras. E foram dez meninos e duas professoras pro Rio. Ficaram lá uma semana, no Museu Nacional de Belas Artes, assistindo o restauro e conhecendo o museu. [...] Alguns que foram lá, nessa viagem, com certeza é uma viagem que é marcante, né. [...] Você vê como é que isso funciona, em uma grande cidade né, um museu importante como é o de Belas Artes, dá a ele um outro... outro estágio, uma outra percepção, outro olhar. Então, isso aí abre um caminho. 
[...] tenho certeza que isso faz uma diferença enorme, né? (E40: Engenheiro civil e presidente da AMAR; João Pessoa, 29/03/2016).

Os cursos ofertados pela Associação Amigos de Areia (AMAR), diferentemente das consultorias e capacitações do Sebrae - que são voltadas para formar e apoiar empreendedores, eram direcionados aos jovens em situação de vulnerabilidade social de Areia, em conformidade com o foco da Associação, que atua na área de cultura, educação patrimonial e qualificação profissional. A fala do presidente dessa Associação (à época da pesquisa) sobre os trabalhos desenvolvidos, enfatiza a contribuição da AMAR para a integração e aproximação dos jovens às artes, por meio de cursos de fotografia, visitas a museus etc. No trecho acima, fica claro a ênfase dedicada em ensinar os jovens "a olhar", isto é, desenvolver outra percepção sobre o espaço em volta, por meio das "excursões de fotografia", por exemplo. Com efeito, parece que o objetivo dessa e de outras formações era desenvolver uma "competência estética instrumental" ou ao menos a capacidade de identificar os padrões sociais que definem "o feio" e "o belo" para uma determinada classe social, tornando os jovens aptos a trabalhar com o turismo, a "agradar" e interagir com os visitantes e turistas. Novas disposições são incorporadas e o repertório deles se amplia a partir de tais capacitações e friç̧ão com novos atores sociais.

Entretanto, apesar do aumento da escolarização e, consequentemente, do capital cultural, observa-se que, enquanto alguns sitiantes parecem mais "propensos" a incorporar novos valores e estilos de vida, outros aparentam ser mais "aferrados" aos valores campesinos tradicionais, demonstrando aversão ou desconfiança em relação ao "novo". Portanto, nem todos os sitiantes conseguem participar do processo de reconversão da mesma maneira. A atividade do turismo é uma opção de trabalho e uma estratégia de reconversão efetivamente para aqueles com maior capital escolar, que conseguem incorporar a racionalidade mercantil e o discurso do empreendedorismo, não por acaso pessoas mais jovens. Situação corroborada pelo dados levantados durante a pesquisa de campo sobre o perfil dos trabalhadores do turismo na Chã de Jardim: $63,3 \%$ do sexo feminino e $36,7 \%$ do sexo masculino; a maioria na faixa etária entre 21 e 35 anos (80\%); quanto a escolarização, o mesmo percentual é obtido para pessoas que já haviam concluído o segundo grau, outros $10 \%$ estavam cursando uma faculdade/ensino superior; e outros $10 \%$ já possuíam nível de ensino superior completo.

No caso em questão, deve-se reter a ideia de que a figura do empreendedor é valorizada positivamente, porque traduz um deslocamento em sentido ascendente, isto é, uma "reconversão para cima", que confere prestígio e permite ascender a uma melhor posição no espaço social. Além disso, o empreendedor é percebido como alguém que tem "coragem de assumir riscos" dentre outras qualidades excepcionais, agrupadas na ideia de "espírito empreendedor". Em síntese, a figura do empreendedor é associada à de patrão (ou, no mínimo, à aspiração de "ser seu próprio patrão", ou seja, não estar submetido a outrem). Porém, no Brejo paraibano, poucos foram os sitiantes que realmente assimilaram o "espírito do empreendedorismo" e, em geral, pessoas que já possuíam algum capital simbólico e econômico. Observou-se com mais frequência reconversões produtivas horizontais, isto é, um deslocamento a partir do abandono da atividade agrícola, que é substituída por uma atividade assalariada mais valorizada socialmente. De qualquer forma, o maior acesso e a elevação do nível de escolarização está sendo fundamental, assentando-se na ideia "estude para ser alguém na vida", a qual é propagada pelas mães e repetida cotidianamente pelos jovens da comunidade Chã de Jardim.

\section{Considerações Finais}

Em consonância com o objetivo de entender as condições de possibilidade da reconversão social dos sitiantes e a relação entre este fenômeno e o desenvolvimento do turismo no município de Areia, ao longo deste artigo, apresentou-se o contexto histórico de evolução do turismo na cidade de Areia, evidenciando-se que o desenvolvimento da oferta turística na Comunidade Chã de Jardim, entre os anos 2006 e 2013, parece ser um ponto de inflexão na trajetória de alguns sitiantes, ao oportunizar que estes se tornem novos pequenos-patrões. A inserção da Chã de Jardim na oferta turística deu-se mais precisamente já no estágio de consolidação do turismo em Areia, momento em que a procura aumenta e o território rural passa a ser percebido como espaço de lazer, tendo suas tradições e identidade ressignificadas. Dessa forma, conclui-se que há uma correlação entre o desenvolvimento do setor de turismo, a ressignificação do território rural e a reconversão dos sitiantes na cidade de Areia.

Quanto aos significados da reconversão de pequeno produtor rural para empreendedor no ramo de turismo, observou-se que para além dos aspectos objetivos (renda, acesso a bens de consumo etc.), para 
os sitiantes significa uma mudança de status e uma mudança de racionalidade. A adesão à ideologia do empreendedorismo atrelada a maior escolarização dos jovens proporciona uma reestruturação no volume de capital simbólico e capital cultural para uma parte deste grupo social. Isso parece resultar na reconfiguração do campo de forças e das posições sociais dos agentes envolvidos no "jogo do turismo", isto é, nas lutas simbólicas por prestígio e poder entre sitiantes e herdeiros da aristocracia rural, algo que, dado os limites desse gênero textual, não foi possível aprofundar nesse artigo, mas que foi explorado em outros trabalhos acadêmicos da autora (ver Oliveira ,2018).

Verificou-se que as chances e oportunidades de mobilidade social, que antes eram remotas, já que a tendência entre os agricultores familiares era que seus filhos continuassem vivendo da agricultura e seguindo valores tradicionais, são bem mais concretas atualmente. No entanto, a produção associada ao turismo e a ideologia do empreendedorismo atendem a um novo perfil de sitiante. Dotado de maior capital cultural porque mais escolarizado, esse sitiante pôde fazer a opção de permanecer no campo, tornando-se um trabalhador pluriativo. Assim, entre os mais jovens, uns passaram a combinar o assalariamento, ao menos em tempo parcial, no serviço público, no comércio ou no setor de serviços, com a agricultura. Porém, os jovens praticamente abandonaram essa atividade, o que explica porque "botar um roçado" é algo realizado majoritariamente por idosos. Em geral, são esses jovens, mais escolarizados, que se voltaram para o empreendedorismo, seja no comércio seja no turismo, abrindo o próprio negócio e, assim, se tornaram patrões de outros sitiantes. Ou seja, a escolarização é crucial, tanto como meio para reconversão produtiva e social como para ressignificação dos valores camponeses.

Ademais, os dados levantados permitem concluir que: 1) a criação de postos de trabalho na própria localidade, ainda que precários e temporários, dá condição para que os jovens (especialmente as mulheres) permaneçam estudando e não precisem migrar, como fizeram muitos de seus antepassados sitiantes; 2) a inserção no mercado do turismo por meio de uma oferta liderada pelos próprios sitiantes é uma importante via de reconversão social, pois lhes proporciona um mínimo de reconhecimento social necessário à elevação da autoestima, para se sentir "alguém" (com acesso ao mercado de consumo) que tem sonhos e que tem o que "trocar" com outros grupos sociais. Ficou demonstrado também que tal inserção não seria possível sem a elevação da escolarização dos jovens sitiantes, condição necessária para adoção de uma racionalidade mercantil, que coloca metas e sonhos como sinônimos. Vale destacar que tal escolarização foi, de certo modo, "financiada" pelo sacrifício da migração das gerações passadas.

Sem dúvida, o acesso à educação pode redefinir os horizontes de possibilidades dos jovens sitiantes. Ainda mais se isso estiver integrado a políticas públicas de desenvolvimento territorial que sejam bem planejadas e executadas. Entretanto, a partir desse estudo de caso, observou-se que nem todos vão se tornar patrões ou empreendedores, pois nem mesmo isso é produto de uma escolha consciente, já que as chances de êxito na escolarização e de reconversão parecem ser predeterminadas pelas competências e disposições sociais adquiridas (habitus), trajetória familiar e capital simbólico acumulado pelos indivíduos dentro e fora de sua comunidade.

Por fim, destaco que este trabalho contribui para evidenciar que a reconversão e a mobilidade social por meio da estratégia de inserção na oferta turística não devem ser compreendidas como fenômenos isolados ou como resultados da determinação individual de uma pessoa ou grupo social, mas, sim, devem ser analisados a partir do contexto mais amplo de mudanças sociais, econômicas, políticas e culturais, observando-se as ações de agentes internos e externos e as disputas culturais e ideológicas em jogo, as quais muitas vezes passam desapercebidas. Disputas e lutas simbólicas que abrangem o setor do turismo, haja vista que ele é um campo significativo das práticas culturais contemporâneas. Ademais, a investigação realizada permitiu demonstrar a pertinência dos conceitos bourdieusianos, ao tratar das lutas simbólicas por status quo e poder associados à reconversão social dos sitiantes da Chã de Jardim ao assumirem a condição de empreendedores no turismo rural.

\section{Bibliografia}

Almeida, A. A. 1994. Brejo paraibano: contribuição par ao inventário do patrimônio cultural. João Pessoa: Secretaria de Educação e Cultura, Departamento de Produção Gráfica.

Almeida, H. 1980. Brejo de Areia. 2ed. João Pessoa: Editora Universitária/UFPB.

Alves, E. P. M. 2017. O consumo da tradição e a fruição do "inautêntico": cultura e mercado nas festas-espetáculo do ciclo juninos no Nordeste. Revista de Ciências Sociais. Fortaleza, v.48, n. 1, p.208-244, jan./jul. Disponível em: <http://www.periodicos.ufc.br/revcienso/article/view/18886/29617> Acesso em: 20 jun. 2017. 
Barbosa, Aloizio Lima. 2016. A Concórdia do Sucesso: O sentido da ação para pessoas do meio empreendedor - ensejos de uma inscrição moral. 149 f. Dissertação (Mestrado em Sociologia) Universidade Federal de Pernambuco, 2016. Disponível em: <repositorio.ufpe.br/handle/123456789/17498> 25 Maio, 2017.

Bourdieu, P. 2007 [1979]. A Distinção - crítica social do julgamento. São Paulo: Edusp; Zouk.

Bourdieu, P. 1996 [1994]. Razões práticas: Sobre a teoria da ação. Tradução: Mariza Correa - Campinas, SP: Papirus.

Bramante, L., Maglio, F. N. \& Roque, A. M. 2012. Um mistério a ser desvendado: panorama do turismo rural brasileiro, políticas públicas e dinâmica rural. In: ATAS DO VIII CITURDES. 25-27 de junho de 2012. UTAD, Chaves, Portugal. Disponível em: <http://www.pasosonline.org/Publicados/pasosoedita/ pasosrep7.pdf> Acesso em: 5 out. 2012.

Brasil. Ministério do Turismo. 2010. Turismo rural: orientações básicas. Secretaria Nacional de Políticas de Turismo, Departamento de Estruturação, Articulação e Ordenamento Turístico, Coordenação Geral de Segmentação. 2.ed - Brasília: Ministério do Turismo. Disponível em: <http://www.turismo. gov.br/sites/default/turismo/o_ministerio/publicacoes> Acesso em: 17 ago. 2017.

Brasil. Ministério do Turismo; Serviço de Apoio às Micro e Pequenas Empresas; Associação de Culturas Gerais. 2011. Manual para o desenvolvimento e integração de atividades turísticas com foco na produção associada. Brasília: Ministério do Turismo. Disponível em: <www.turismo.gov.br/images/ Manual_de_Producao_Associada_ao_Turismo.pdf > Acesso em: 03 fev. 2016.

Camacho, Vania Claudia da Gama. 2013 O Ensino de Piano na Paraíba: memórias, lugares e práticas musicais (1945 - 1985). 2013. 278 f. Tese (Doutorado em Educação). Universidade Federal da Paraíba, João Pessoa.

Carneiro, M. J. (coord.). 2012. Ruralidades Contemporâneas: modos de viver e pensar o rural na sociedade brasileira. Rio de Janeiro: Mauad X: FAPERJ.

Costa, Sylvio de Sousa Gadelha. 2009. Governamentalidade neoliberal, Teoria do Capital Humano e Empreendedorismo. Educação e Realidade. 34(2): 171-186 mai/ago 2009. Disponível em: <http://www. seer.ufrgs.br/educacaoerealidade/article/viewFile/8299/5537> Acesso em: 04 mar. 2018.

Costa, Alessandra Mello da; BARROS, Denise Franca; CARVALHO, José Luis Felicio. 2011. A dimensão histórica dos discursos acerca do empreendedor e do empreendedorismo. Revista Administração Contemporânea. [online]. V.15, n.2, pp.179-197. Disponível em: < http://dx.doi.org/10.1590/ S1415-65552011000200002 > Acesso em: 05 mar. 2018.

Cunha, L. H. 2009. Sobre o conceito de reconversão. In: I Seminário do Projeto Políticas Públicas - Reconversões produtivas e recomposições identitárias no nordeste brasileiro: um olhar a partir do mundo rural e de suas conexões com o urbano, Campina Grande, UFCG.

Duarte, T. 2009. A possibilidade da investigação a 3: reflexões sobre triangulação (metodológica). In: CIES e-WORKING PAPER N. ${ }^{\circ}$ 60/2009. Disponível em: https://repositorio.iscte-iul.pt/bitstream/10071/1319/3/ CIES-WP60\%20_Duarte.pdf Acesso em: 18 set. 2017.

Empresa Paraibana de Turismo - PBTur. 2016. Relatório do Fluxo Global. João Pessoa.

Fiúza, A. F., et al. 1998. Uma história de Areia. João Pessoa: Editora Universitária /UFPB.

Fontanella, F. I. 2005. A Estética do Brega: cultura de consumo e o corpo nas periferias do Recife. 2005. 112f. Dissertação (Mestrado em Comunicação) Universidade Federal de Pernambuco. Disponível em: <http://repositorio.ufpe.br/bitstream/handle/123456789/3455.pdf> Acesso em: 17 jan. 2018.

Fórum Regional de Turismo Sustentável do Brejo Paraibano - FRTSB-PB. 2010. Estatuto Social. Bananeiras.

Galvão, S. F. S. 2012. Interfaces cultural, política e organizacional do projeto "Caminhos do Frio - Rota Cultural" no contexto da regionalização do turismo no brejo paraibano. 2012. 214f. Dissertação (Mestrado) Natal: Universidade Federal do Rio Grande do Norte. Disponível em: <http://bdtd.bczm. ufrn.br/tde_arquivos/44/4805/Publico/SueniaFSG_DISSERT.pdf > Acesso em: 25 fev. 2017.

Garcia Jr. A. R. 1993. Reconversion des élites agraires. [Du pouvoir local au pouvoir national]. Études rurales. $\mathrm{n}^{\circ} 131-132$. Droit, politique, espace agraire au Brésil. pp. 89-105. Disponível em: <https:// etudesrurales.revues.org/1223> Acesso em: 13 abr. 2017.

Garcia Jr. A. R. 1989. O Sul, Caminho do roçado: estratégias de reprodução camponesa e transformação social. São Paulo: Marco Zero.

Giuliani, G. M. 1990. Neo-ruralismo: o novo estilo dos velhos modelos. RBCS/ANPOCS, n. 14, ano 5.

Governo do Estado da Paraíba. 2014. Secretaria do Turismo e do Desenvolvimento Econômico. Caminhos do Frio: Perfil do Turista Areia - comparativo 2011, 2012, 2013 e 2014. Empresa Paraibana de Turismo, João Pessoa. 
Heredia, B. M. A. 1979. A morada da vida: trabalho familiar de pequenos produtores do Nordeste do Brasil. Rio de Janeiro: Paz e Terra.

Heredia, B. M. A. 1989. Formas de dominação e espaço social: a modernização da agroindústria canavieira em Alagoas. São Paulo: Marco Zero.

Instituto Brasileiro de Geografia e Estatística - IBGE. 2015. Pesquisa Nacional por Amostra de Domicílios: Síntese de indicadores. Disponível em: <https://ww2.ibge.gov.br/home/estatistica/populacao/ pnad2012/default_sintese.shtm> Acesso em: 07 jul. 2017.

Instituto Brasileiro de Geografia e Estatística -IBGE Cidades. 2020. Censo Agropecuário: Dados Areia. Rio de Janeiro, 2017. Disponível em: < https://cidades.ibge.gov.br/brasil/pb/areia/panorama> Acesso em: 22 outubro. 2020.

Instituto do Patrimônio Histórico e Artístico Nacional- IPHAN. 2009. O festival de artes - Areia - PB. Brasília, DF: Iphan / Programa Monumenta.

Magalhães, A. 2009. Socialização do Espaço Urbano: como um festival de artes interferiu na relação indivíduo/cotidiano na cidade de Areia, Brejo paraibano, na década de 70. 2009. 128f. Dissertação (Mestrado em Sociologia). Universidade Federal da Paraíba: João Pessoa. Disponível em: <http:// tede.biblioteca.ufpb.br/tede/1/arquivototal.pdf> Acesso em: 20 mar. 2017.

Marques, A. L., Araújo, D. C. \& Diniz, L.S. 2016. Novo Rural Brasileiro nos Brejos do Estado da Paraíba. Revista GeoTemas. Pau dos Ferros, Rio Grande do Norte, Brasil, v.6, n.2, p.47-58, Jul./Dez.

Menezes, M., Malagodi, E., \& Moreira, E. R. 2013. Da usina ao assentamento: os dilemas da reconversão produtiva no Brejo Paraibano. Estud. Soc. e Agric., Rio de Janeiro, v. 21, n. 2, pp. 332-358.

Moreira, E., \& Targino, I. 1997. Capítulos de Geografia Agrária da Paraíba. João Pessoa: Editora Universitária/ UFPB.

Oliveira, Josilene Ribeiro de. 2018. "Do sítio sim, besta não!": reciprocidade, dons e lutas simbólicas em jogo no turismo em Areia, Paraíba-Brasil. 583 f. (Tese de doutorado em Sociologia) Universidade Federal de Pernambuco.

Oliveira, Josilene Ribeiro de. 2018. Trabalho e Produção Associada ao Turismo: tensões e rupturas no processo de construção da identidade de mulheres na Comunidade Rural Chã de Jardim. Norus Novos Rumos Sociológicos, v. v.6, n.9, p. 161-201.

Sancho, Federico. 2010. Agricultural and rural entrepreneurship: concepts for modeling development. Comuniica. Year 5. Janaury - July, 2010. Disponível em: <http://repiica.iica.int/docs/b2032i/b2032i. pdf> Acesso em: 30 jul. 2017.

Serviço Brasileiro de apoio às Micro e Pequenas Empresas - SEBRAE. 2014. Territórios da Cidadania: Riquezas de um novo Brasil. Brasília-DF. Disponível em: <http://www.bibliotecas.sebrae.com.br/ chronus/ARQUIVOS_CHRONUS/bds/bds.nsf/90860905e4c63a1dff070b05b396f0d1/\$File/5182.pdf> Acesso em: 30 jul. 2017.

Sigaud, L. 1979. Os clandestinos e os direitos: estudo sobre trabalhadores da cana-de-açúcar de Pernambuco. São Paulo, Livraria Duas Cidades.

Sigaud, L. 1996. Direito e Coerção Moral no Mundo dos Engenhos. Revista Estudos Históricos. V. 9, n. 18. P. 361-388.

Silva, L. 2009. Casas de Campo: Etnografia do Turismo Rural em Portugal. Lisboa: ICS.

Soares, T. 2017. Ninguém é perfeito e a vida é assim": a música brega em Pernambuco. 1. ed. Recife/ PE: Outros Críticos.

Wanderley, M. N. B. 2003. Agricultura familiar e campesinato: rupturas e continuidades. Estudos Sociedade e Agricultura, Rio de Janeiro, n.21, p. 42-61, out. Disponível em: <https://wp.ufpel.edu. br/leaa/files/2014/06/Texto-6.pdf> Acesso em: 15 mai. 2013.

Wanderley, M. N. B.\& Favareto, A. 2013. A singularidade do Rural Brasileiro: implicações para as tipologias territoriais e a elaboração de políticas públicas. In: MIRANDA, C. \& SILVA, H. (Orgs.). 2013. Concepções da Ruralidade Contemporânea: as singularidades brasileiras. Brasília: IICA. (Série Desenvolvimento Rural Sustentável; v.21).

Woortmann, K. 1990. Migração, família e campesinato. Revista Brasileira de Estudos de População (Campinas), v.7, n.1, p.35-53. Disponível em: < https://www.rebep.org.br/revista/article/view/546> Acesso em 22 fev. 2017.

Woortmann, E. F. 1983. O Sítio Camponês. Anuário Antropológico/81. Edições Tempo Brasileiro. Rio de Janeiro.

Yúdice, George. 2002. El Recurso de la Cultura: Usos de la cultura en la era global. Editorial Gedisa: Barcelona. 


\section{Notas}

1 Optou-se por usar a categoria 'sitiante' em detrimento de camponês ou agricultor familiar para designar os interlocutores principais da pesquisa, tendo em vista que representa um identidade social para os nativos, usada para diferenciar os moradores dos sítios em áreas rurais das pessoas que moram na cidade (os citadinos ou "da rua") ou na casa da fazenda (o fazendeiro e sua família).

2 O primeiro tombamento do centro histórico de Areia foi realizado pelo Instituto do Patrimônio Histórico e Artístico do Estado da Paraíba, em 1979, através do Decreto $n^{\circ}$. 8.312. O segundo tombamento incluiu, além do centro histórico, o patrimônio paisagístico e foi concedido pelo Instituto do Patrimônio Histórico e Artístico Nacional (IPHAN), em 2005, sob o Processo N 1489-T-02, sendo homologado e publicado no Diário Oficial da União através da Portaria n. $73^{\circ}$, em 2006.

3 O Programa Monumenta foi concebido na década de 1990, mas apenas a partir de 2003 tornou-se uma política governamental, sob responsabilidade do Ministério da Cultura, voltada para o desenvolvimento urbano das cidades sob proteção federal, isto é, tombadas pelo IPHAN. O Programa alia preservação do patrimônio histórico e desenvolvimento local, focando na geração de emprego e renda e estímulo à inclusão social, por meio de uma gestão descentralizada, com a criação de fundos municipais de preservação do patrimônio e de parcerias com outros órgãos. (IPHAN, 2009).

4 Oficialmente formalizado em 1940, em comemoração ao centenário do pintor (em 1943), o Museu Casa de Pedro Américo é um dos mais visitados do município. Além do Teatro Minerva, a cidade dispõe de outros três museus abertos à visitação: Museu da Cachaça e da Rapadura, Museu Regional (Mura) e o Casarão José Rufino.

5 Derivada da tradição escolástica, a palavra latina habitus, originalmente, traduz a noção grega de hexis, utilizada por Aristóteles para designar as características do corpo e da alma adquiridas em um processo de aprendizagem. Posteriormente foi retomada por Émile Durkheim, no livro A evolução pedagógica (1938) no qual o autor discute as influências da educação sobre crianças em sociedades tradicionais e internatos, para designar um estado interior e profundo, que orienta as ações dos indivíduos de forma durável (SETTON, 2002). Assumindo uma perspectiva nova, Bourdieu usa o termo, pela primeira vez, em um artigo de 1962, em que investiga "As relações entre sexos na sociedade camponesa" do Béarn para descrever a disjunção traumática entre as competências e as expectativas incorporadas do homem rural e das mulheres locais, que, estando mais abertas à influência cultural da cidade, tinham passado a perceber e avaliar esses homens através de lentes urbanas que desvalorizavam radicalmente os seus modos, tornando-os, desse modo, "incasáveis" (WACQUANT, 2006, p. 17). De acordo com Wacquant (2006), mais ou menos na mesma época, Bourdieu usou o termo em Le déracinement, para se referir à "disposição geral e permanente em relação ao mundo e em relação aos outros".

6 O Serviço Brasileiro de Apoio às Micro e Pequenas Empresas (Sebrae) é apontado como principal fomentador do empreendedorismo no Brasil, sendo responsável desde a década de 1980 por estruturar uma concepção moral sobre o que é empreender, ao elaborar um conjunto de ações e recomendações que devem ser seguidas por consultores e empreendedores (BARBOSA, 2016). Na área rural, é o Serviço Nacional de Aprendizagem Rural (Senar) também atua nesse sentido, oferecendo assistência técnica e gerencial aos produtores rurais (pequenos ou grandes), em todo território nacional, visando a formação profissional rural e a promoção social de jovens e adultos no meio rural (Oliveira, 2018).

7 Duas usinas se estabeleceram no Brejo: Usina Tanques, em Alagoa Grande; e Usina Santa Maria, em Areia. Esta última se estabeleceu nos anos 1930, iniciando os trabalhos de moagem em 1932. Graças ao incentivo do Programa Proalcool, uma destilaria de álcool foi construída em 1978, em anexo a Usina Santa Maria, aumentando a demanda por cana-de-açúcar e levando ao arrendamento de vários plantios nas terras de engenhos da região, que acabaram por entrar em "fogo morto", tendo por consequência a diminuição do número de engenhos em atividade (Garcia Jr. 1989; Moreira \& Targino, 1997).

8 Sobre as estratégias e processo de reconversão da aristocracia rural, sugere-se a leitura dos seguintes trabalhos: "Reconversion des élites agraires. [Du pouvoir local au pouvoir national] ", de Afrânio R. Garcia Jr, e a tese da autora - "Do sítio sim, besta não!": reciprocidade, dons e lutas simbólicas em jogo no turismo em Areia, Paraíba-Brasil.

9 'Era dos Festivais'é o título do livro de Zuza Homem de Mello, lançado em 2003, em que o autor descreve os bastidores do que se tornaria conhecido como a época de ouro da música e da cultura popular brasileira. Realizados entre 1965 e 1972, os festivais de música popularizaram e tornaram conhecidos nomes como Elis Regina, Nara Leão, Chico Buarque, Jair Rodrigues, Caetano Veloso e Geraldo Vandré, os quais se tornaram ícones da Música Popular Brasileira (MPB) (Magalhães, 2009).

10 Originalmente concebido como atividade de encerramento de um evento acadêmico, no qual produtores locais, estudantes, representantes de instituições públicas e privadas e alguns convidados discutiam ações para melhoria da produção da cachaça na Paraíba, o Bregareia ganhou proporções maiores quando a prefeitura local "comprou a ideia" e patrocinou shows musicais de estilo Brega, em paralelo à degustação ofertada pelos produtores de cachaças da microrregião do Brejo. O objetivo era dar visibilidade e impulsionar a produção e o consumo da cachaça produzida no Brejo.

11 Em 2012, segundo pesquisa realizada por Galvão (2012), havia 05 meios de hospedagem na cidade de Areia. Conforme os levantamentos empreendidos por mim, até 2017, existiam oito pousadas e hotéis na cidade, compreendendo uma oferta de cerca 200 leitos, no total. Verificou-se também a oferta de meios de hospedagem alternativos, em residências familiares, por meio da plataforma Airbnb, contabilizando-se mais cinco outros locais para hospedagem no município, com mais 16 leitos declarados.

12 A Rota Cultural Caminhos do Frio recebe essa denominação porque baseada na história e cultura regional e apresenta delimitado seu período e ordem da visitação. Em 2017, a Rota incluiu as seguintes cidades: Areia, Pilões, Remígio, Solânea, Serraria, Bananeiras, Matinhas, Alagoa Nova e Alagoa Grande. Iniciando-se sempre por Areia, a Rota dedicou uma semana de atividades em cada cidade, no período de 03 de julho a 03 de setembro de 2017.

13 Segundo dados levantados por Garcia Jr. (1989), em 1909 havia 109 engenhos em atividade em Areia, todos cultivando e moendo cana de açúcar para produção de rapadura e cachaça; em 1949, havia 97 engenhos; em 1953, esse número caiu para 91; e em 1980, havia apenas 37 engenhos em atividade.

Recibido:

$21 / 11 / 2019$

Reenviado:

$22 / 05 / 2020$

Aceptado:

$28 / 06 / 2020$

Sometido a evaluación por pares anónimos 